\title{
Conceptualizations of representation forms and knowledge organization of high school teachers in Finland: "magnetostatics"
}

\author{
Sharareh Majidi ${ }^{1}$, Markus Emden ${ }^{2^{*}}$ \\ ${ }^{1}$ Department of Physics, University of Helsinki, Helsinki, Finland \\ 2,* Department of Chemistry Education, Universität Duisburg-Essen, Essen, Germany \\ For correspondence: sharareh.majidi@helsinki.fi
}

\begin{abstract}
One of the main components of teachers' pedagogical content knowledge refers to their use of representation forms. In a similar vein, organizing concepts logically and meaningfully is an essential element of teachers' subject matter knowledge. Since subject matter and pedagogical content knowledge of teachers are tightly connected as categories forming their knowledge base, it is reasonable to expect that representation forms and organization of knowledge are related. In order to find out how far these two facets depend on each other, two Finnish upper secondary physics teachers' answers to an electronic questionnaire were analysed as case studies. Questions varied from teachers' organization of knowledge to their representation forms regarding the topics of "magnetic flux density" and "Ampère's law." A concept map constructed by one teacher, led us to an improved description of teachers' knowledge organization. In addition, observed and analysed lessons given by the second teacher shed light on representation forms. Organization of knowledge of the studied topics was investigated by means of recognizing the core concepts, and then interrelations between the other concepts. So, the study could advise physics teacher to more systematically plan and organize their teaching of the studied topics. Other findings illuminate useful representation forms that physics teachers apply during their teaching such as suiting experiments, explanations, and models. Thus, our conceptualization emphasize for teachers to reflect on effective ways to organize their knowledge and, consequently, to select adequate representation forms.
\end{abstract}

Keywords: Knowledge Organization, Representation Forms, High school teachers, Concept Map, Magnetic flux density, Ampère's law

\section{Introduction}

Physics has always been one of the most challenging school subjects for students. Therefore, it is essential to be aware of the most effective ways to teach physics. One of the most important factors that affect learning and teaching physics is teachers' organization of physics topics in their instruction. In general, teachers must know how to organize their subject matter knowledge (SMK); considering logical and meaningful organization of content knowledge forms the basis for a careful design of teaching (Bransford et al, 1999; Mäntylä, 2011; Majidi, 2012). As Shulman (1986, p. 9) stated that "in different subject matter areas, the ways of discussing the content structure of knowledge differ", each school subject needs to find its individual way to address questions of effective organization of knowledge. There is, according to Abell (2007), a lack of such a discussion of content structure and relations among concepts with regard to physics in secondary education. One way to comprehend the relations between concepts in physics is studying its knowledge organization (Bransford et al, 1999; Koponen \& Pehkonen, 2010; Mäntylä, 2011).

Experts' knowledge, in any discipline, has a highly organized structure and experts' knowledge is not fragmented. Therefore, without any doubt, gaining organized knowledge is required for teachers in order to enhancing it towards expert knowledge. It is expected to have an immediate impact on effective and useful learning and teaching in science education (Mäntylä, 2011). Examining the SMK of physics teachers, as an example of experts in physics education, might provide us with fruitful understanding of the physics teaching and school relevant content structure of physics. This argument follows from Bransford et al. (1999) who claim that experts already possess an organized content knowledge which mirrors a deeper understanding of their subject matter. Having an organized knowledge, experts can retrieve their knowledge with less effort and more effectively than novices. 
Some researchers state that teachers' knowledge is elusive (Carter, 1993) and that teachers are unaware of the knowledge they possess (Kagan, 1990). There are, however, visualization approaches to the Organization of Knowledge (OrgK), which can inform teachers about the scope of their content knowledge. Concept maps have often been employed to visualize structures of knowledge (Kinchin et al., 2000; Hay et al., 2008) and, by virtue of them being metacognitive tools, allow for deeper interpretations of teachers' thinking and their OrgK (Novak \& Canas, 2006). In their research, Kinshin et al. (2000) distinguished three major structures of knowledge: chain, spoke, and web. One of the key features that distinguishes these major patterns lies in the significance of core concepts (concept with most links attached to it), i.e. its relations to incoming and outgoing links to other concepts. Another, related approach by Koponen and Pehkonen (2010) distinguishes with reference to how concepts are interwoven between linear hierarchies and complex clustering.

In this study, OrgK has been approached by firstly taking into account teachers' responses to the section of "organization of magnetostatics concepts" from online questionnaire. Teachers were requested to indicate their priorities by placing numbers in the boxes to show the ordering of their views about magnetostatics concepts. After analysing the results of the questionnaires, we recognized the most potential teachers who possessed the most powerful responses. Next, we found the opportunity to conduct case studies of those potential teachers. Furthermore, deeper insight to OrgK of teachers has been emerged by considering the most relevant core concepts and clusters, and subsequently the interrelatedness of the concepts throughout the concept maps of teachers.

It has often been suggested that teachers or curriculum materials (such as textbooks) which possess rich content knowledge but make poor use of different representation forms, are not successful to convey knowledge (Shulman, 1986; Geddis \& Wood, 1997). Therefore, another important factor in physics education appears to be elaborating how content knowledge from an academic domain (physics) can successfully be translated into secondary science education. Knowledge of these translation processes is referred to as pedagogical content knowledge (PCK) (Shulman, 1986). According to Shulman's (1986) conceptualization, PCK embraces "the most powerful analogies, illustrations, examples, explanations, and demonstrations - in a word the ways of representing and formulating the subject that makes it comprehensible for others" (p. 9).

In this study, the representation forms (ReFs) for teaching "magnetic flux density" and "Ampère's law" have been inferred by expressing teachers' opinions regarding "teaching magnetic flux density" and "teaching Ampère's law" through Likert scale and open ended questions. So, teachers' opinions about the main ReFs which were frequently employed in their teaching of "magnetic flux density" and "Ampère's law" were questioned. Again, more profound information about ReFs of teachers obtained from observation of lessons of potential teachers which deepened our analysis.

We chose these topics because they are prominent theories in secondary science courses on electricity and magnetism; students require a high cognitive load to deal with difficult calculus (Manogue et al, 2006); and they hold naïve and superficial understanding of these topics (Erickson, 1994); a variety of misconceptions and difficulties has been reported in this regard (Guisasola, 2004); and finally the lack of its investigation in the history of research in science teaching (Abell, 2007) encourage us to focus on these topics. In this study we address these questions:

1. How do high school teachers organize their knowledge of magnetic field density and Ampère's law? Can upper secondary school teachers' organization of their SMK regarding magnetic field density and Ampère's law be captured in a concept map?

2. Which representation forms do high school teachers employ when teaching magnetic field density and Ampère's law?

3. Can choice representation forms be related to science teachers' organization of their SMK?

\section{Background}

There are many studies that investigate science teachers' SMK and PCK, some of which consider teachers' SMK to be connected to teachers' PCK but as a distinct category (Parker \& Oliver, 2008; Shulman, 1987), and again others assume SMK as a well-defined component of PCK (Geddis \& Wood, 1997; Hashweh, 2005; Loughran et al, 2004; Rollnick, 2008). Shulman (1986), who was the innovator of PCK, states that amongst others it includes two main categories: teachers' knowledge of representation forms/strategies and their knowledge of students' misconceptions/difficulties. Also, Geddis and Wood (1997) stated that PCK assists teachers to translate their SMK into forms that are more easily accessible for students. They argued that ReFs work on the ultimate stage of pedagogical 
translation of SMK presupposing professional reflection on subject matter representation and the topic's curricular saliency, consideration of students' prior knowledge, and deciding on suiting instructional strategies and teaching materials. Loughran et al. (2004) employed content representation and a professional and pedagogical experience repertoire to portray teachers' PCK. The former captures teachers' SMK: key and alternative ideas of a given content, their understanding, ambiguities, beliefs of effective sequencing, and ways to scaffold, i.e. to organize the ideas; the latter two aspects assist teachers to reflect features of their PCK through describing teaching procedures, curriculum issues, and students' alternative concepts. The issue if SMK is embedded in PCK has been investigated by Rollnick et al. (2008). They suggested a model for PCK which distinguishes between teachers' knowledge and their manifestations of knowledge. The former includes different kinds of knowledge relevant to education: SMK of teachers, knowledge of students, general pedagogical knowledge, and knowledge of context. The latter refers to knowledge about representations, curricular saliency, assessment, and topic specific instructional strategies. They assume that PCK initiates from teachers' knowledge and extends towards their manifestations of knowledge. In 2012, they conducted research to examine concept maps as representations of teachers' meaning- making. Four categories emerged from teachers' concept maps including no implicit meaning, SMK focus, PCK context focus, and PCK strategy focus. They concluded that teachers' understanding of SMK developed by means of concept maps. Hashweh (2005) suggested a model in which teachers' beliefs and knowledge were juxtaposed with their pedagogical construction of a unit on photosynthesis. His approach of presenting PCK for a specific topic is concurrent with van Driel et al. (1998) who emphasized that "in our view, the value of PCK lies essentially in its relation with specific topics." Therefore, PCK is to be discerned from general pedagogical knowledge on one hand, and from subject-matter knowledge per se on the other hand (p. 691). Accordingly, in this paper ReFs and OrgK of teachers will be considered for two particular topics of magnetostatics. In this study we did not investigate if SMK and PCK are distinct or if one evolves from the other, but here we state OrgK bases on SMK and ReFs relies on PCK, therefore we need to address both if we want to find out about their intricacies.

We believe that teachers have accumulated a certain content knowledge which they need to organize and prepare before representing it educationally. It is after organizing their SMK that teachers employ a variety of pedagogical skills and ReFs to translate their SMK for students. They express their PCK in/through this process of translation. Consequently, we assume SMK to be an essential component of their PCK.

If the organization of knowledge is integral to PCK, as are ReFs, and if PCK really does evolve content specifically, valuable information on the complex interplay between those different facets of PCK could be gained from case studies on different topics. Therefore, in this study we want to investigate the interplay between OrgK and ReFs regarding these two topics: magnetic flux density, Ampère's law. As suggested above, literature has not yet discussed OrgK's relation to SMK conclusively; something we want to address in this study. At the same time, we will investigate ReFs' status in teachers' PCK on both the topics. The following table summarizes ideas of OrgK and ReFs from the previous literature:

Table 1. Approaches to organization of knowledge and representation forms

\begin{tabular}{|c|c|c|}
\hline & OrgK includes & ludes \\
\hline $\begin{array}{l}\text { Shulman, } \\
1986 \text { (p. 9) }\end{array}$ & $\begin{array}{l}\text { Different ways to } \begin{array}{l}\text { organize } \\
\text { concepts } \\
\text { which } \\
\text { constitute }\end{array} \\
\text { teachers' content knowledge }\end{array}$ & $\begin{array}{l}\text { A variety of ways to represent and } \\
\text { formulate the subject including } \\
\text { analogies, illustrations, examples, } \\
\text { explanations, and demos }\end{array}$ \\
\hline $\begin{array}{l}\text { Geddis \& } \\
\text { Wood, } 1997\end{array}$ & $\begin{array}{l}\text { Structuring and segmenting the } \\
\text { subject matter knowledge }\end{array}$ & $\begin{array}{l}\text { Representation of subject matter } \\
\text { including examples, models, } \\
\text { analogies, simulations, metaphors, and } \\
\text { illustrations. It is the end product of } \\
\text { pedagogical transformation and } \\
\text { knowledge about learners and SMK }\end{array}$ \\
\hline $\begin{array}{l}\text { Loughran } \\
\text { al. } 2004\end{array}$ & $\begin{array}{l}\text { Effective sequencing of big ideas } \\
\text { and approaches to the framing of } \\
\text { ideas (explained through Content }\end{array}$ & $\begin{array}{l}\text { Teaching procedures including probes, } \\
\text { POE (Predict, Observe, Explain), } \\
\text { translation activities, modelling with }\end{array}$ \\
\hline
\end{tabular}


Representation CoRe)

Hashweh, 2005

$\begin{aligned} & \text { Knowledge of approaches or } \\ & \text { different ways of relating topics to } \\ & \text { demonstrations, Analogies, examples, } \\ & \text { other disciplines entities (e. g. explanations, representations } \\ & \text { concepts, principles, })\end{aligned}$

different materials, analogies, using demons and models

Although it is evident from Table 1 that OrgK is considered an important aspect of SMK, hardly any of these have attempted to visualize teachers' OrgK, i.e. provide a manifestation of their SMK. Teachers presumably possess some kind of OrgK, which aids storing in their long term memory; if a structure such as this exists, it arguably enhances their teaching by, e.g., suggesting the most suitable ReFs, and should, therefore, be beneficial to learning (Bransford et al. 1999). This again, underlines why investigating teachers' OrgK - and by extension their use of ReFs - must not be neglected in the study of PCK.

\section{Design and method}

In this research, we sought to investigate "organization of knowledge" (OrgK) of expert science teachers and their preferred "representation forms" (ReFs) by questionnaires, concept maps, and classroom observation.

We contacted and invited 89 Finnish high schools Physics teachers to participate in our survey. The questionnaire was inspired by Trends in International Mathematics and Science Study (TIMSS) Advanced (2008) for physics teachers. It was designed in an electronic format and consisted of 7 background questions, 1 question about organizing the concepts in terms of their priorities, 18 Likert scale and 20 open ended questions; items on teachers' OrgK and ReFs were newly constructed for the study. Teachers' background was surveyed with regard to: gender, major and minor subjects, years of teaching experience. For construction of OrgK-items, we identified thirteen concepts from two concept maps on electromagnetism from a standard Finnish high school textbook (Hatakka, et al, 2006; p. 24 \& 43). This textbook is representative because among other popular Finnish high school textbooks, it is the only one which contains concept maps after each chapter, so it is more convenient to compare it with concept maps of teachers. These concepts were then presented to the surveyed teachers in English and Finnish forms. Teachers were asked to prioritize these concepts with regard to importance in their teaching. In addition, we provided a concept map with the same thirteen concepts leaving out the relations. It was attached as a supplement to the electronic questionnaire and teachers were free to choose completing the map. The decision for this concept mapping exercise was made on the criticism on traditional static Multiple-choice-tests that these are of limited value in uncovering teaching perspectives (Stoddart et al, 2000). Concept mapping is considered a more flexible technique (Rollnick et al. 2012) with which teachers can individually visualize their knowledge.

Questions about ReFs addressed the frequency and importance teachers attribute to, e.g., examples for and applications of concepts, explanations or justifications, analogies, experiments, visual models (cf. Majidi, 2012). Additional questions concerned students' misconceptions and difficulties about the studied topics. At the end, as an optional exercise we requested teachers to construct a concept map using the magnetostatics concepts, and send it electronically or by post to us.

In total, we received six answers $(6.74 \%)$ from the invited teachers, so we decided to qualitatively analyse the answers regarding the open ended questions. Preliminary analyses showed that two teachers provided particularly rich information. In addition, we found the opportunity to collect more data from observing lessons of one teacher and analysing the optional concept map of the other teacher. Therefore, we decided on conducting a case study with these teachers.

Both the teachers teach Physics in outstanding high schools in Helsinki and have contributed in writing to two different high school textbooks in Finnish. One teacher (Robert) has a minor in computer science and teaches in an international program in a Finnish high school. He is an English native speaker but graduated in Finland and has eleven years of teaching experience in Finland. The other one (Kevin) is a native Finnish speaker, he has taught at a Finnish high school for more than twenty years; he did not specify his minor subject. Considering their years of teaching experience both these teachers can be considered experts. According to Hashweh (2005), who argued "teachers 
pedagogical construction develops through experience," investigations of OrgK and ReFs of these two teachers can shed help clarifying the relations between PCK and SMK.

The OrgK was captured using their prioritization of concepts. Moreover, Kevin provided a concept map which enables deeper analysis of the structural characteristics of his knowledge. He prepared his concept map with Grap tool (Florida Institute for Human and Machine Cognition) and sent it electronically. The organization of his concept map was compared to two concept maps from the Finnish Physics textbook regarding the maps' structures including their concepts and propositions (Majidi \& Mäntylä, 2011).

Identification of ReFs was developed by analysing the responses of the questionnaire's respective section. Analyses of videotaped lessons enhanced our findings. A summary of research approaches and data from two case studies is given in Table 2.

Table 2. Domains for analysing data

\begin{tabular}{lll}
\hline Research Instrument & Data & Main source of data \\
\hline Online questionnaires & $\begin{array}{l}\text { OrgK (Organization of } \\
\text { Knowledge) }\end{array}$ & Kevin \& Robert \\
$\begin{array}{l}\text { (including open ended } \\
\text { and Likert scale } \\
\text { questions) }\end{array}$ & ReFs (Representation Forms) & \\
\hline Classroom observation & Deepening ReFs: & Robert \\
(2 lessons; 2.5 hours) & $\begin{array}{l}\text { examples, experiments, analogies, } \\
\text { etc }\end{array}$ & \\
\hline Concept map & Deepening OrgK: & $\begin{array}{l}\text { Kevin \& high school } \\
\text { physics textbook } \\
\text { (Hatakka, et al, } \\
\end{array}$ \\
& clusters, core concepts, incoming \\
& and outgoing relations & 2008) \\
\hline
\end{tabular}

Thus, the method of this study concerns not only the observation of lessons or evaluating concept maps, but also teachers' responses to the questionnaire regarding their SMK and PCK. Thus, triangulating different methodologies provides more insight into teachers SMK and PCK as a whole (Baxter \& Lederman, 1999).

\section{Results}

Results of this study pertain to two larger areas: OrgK and ReFs. Therefore, results will be discussed in separate sections of responses to questionnaires regarding $\operatorname{OrgK}$, OrgK from the concept map, responses to questions regarding ReFs, ReFs from two observed lessons on Magnetic Flux Density for Moving Charges, Magnetic Flux Density for a Conductive Wire, and Ampère's law, respectively.

Responses to questions regarding organization of knowledge

Basic information on the high school teachers' OrgK was obtained from their ranking of concepts in the questionnaires which is presented in Table 3. 
Table 3. Priorities to show the ordering of their views about concepts by placing numbers from 1 to 13: 1 refers to highest priority and 13 refers to lowest priority concepts

\begin{tabular}{lll}
\hline $\begin{array}{l}\text { Magnetoststics } \\
\text { Concepts }\end{array}$ & $\begin{array}{l}\text { Priorities } \\
\text { of Kevin }\end{array}$ & $\begin{array}{l}\text { Priorities } \\
\text { of Robert }\end{array}$ \\
\hline Magnetic field & 2 & 1 \\
\hline Moving charges & 4 & 10 \\
\hline Electric current & 6 & 7 \\
\hline Right hand rule & 5 & 6 \\
\hline Biot-Savart law & 13 & 8 \\
\hline Ampères law & 9 & 12 \\
\hline Coil & 8 & 9 \\
\hline Wire carrying current & 7 & 5 \\
\hline Pair long wires & 10 & 11 \\
\hline Magnetic flux & 11 & 3 \\
\hline Magnetic flux density & 12 & 2 \\
\hline Magnetic interaction & 1 & \\
\hline Field lines & 3 & \\
\hline
\end{tabular}

As Table 3 indicates, teachers' OrgK was consistent between them for some of the prioritized concepts: their first priority goes to concepts of magnetic field, magnetic interaction; their second priority was field lines; their next ones associate with right hand rule, electric current, wire carrying wire; finally coil, pair long wires, and magnetic flux y had the less priority in teachers' opinion. Nevertheless, these teachers had different opinions about the order of Biot-Savart law, magnetic flux density, Ampère's law, and moving charges. Unlike Robert, Kevin prioritized moving charge and Ampère's law low. Kevin assigned to each of these concepts a comparatively lower priority. On the other hand, Robert prioritized Biot-Savart law and magnetic flux density lower than what Kevin's orders. The possible reasons for this outcome will be discussed later.

Organization of Knowledge from concept maps

In this section, relevant parts of Kevin's concept map are discussed in detail (figure 1). These sketch Kevin's mental conceptions for the topic of magnetostatics. Kevin's concept map includes two meaningful not immediately attached domains of knowledge (figure 1). 

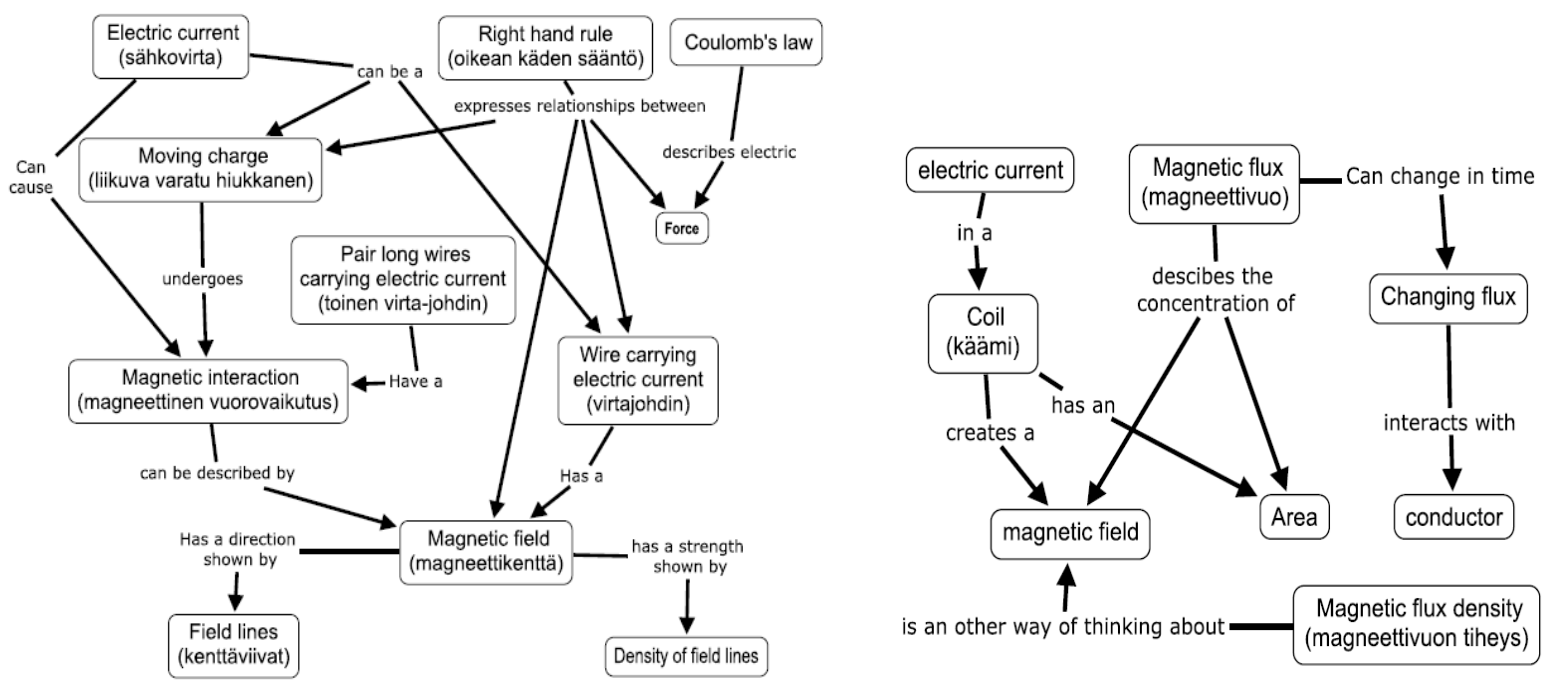

Figure 1. Kevin's concept map: first domain in left side and second domain in right side

In the analysis of Kevin's concept maps, core concepts are shown by bold, while incoming and outgoing concepts are marked with italic.

In the first domain (figure 1), he provides his understanding of the relation between the concepts of magnetic field, magnetic interaction, and right hand rule. These are considered central concepts because of the numerous incoming and outgoing links that are directly attached to them.

- The most central concept in the first domain is magnetic field which includes five attaching links. With regard to links connected to magnetic field, the following connections are mentioned:

- Strength of a magnetic field is showed via density of field lines; direction of magnetic field is showed by field lines; wire carrying current has magnetic field; magnetic interaction can be described by magnetic field.

The next most central concepts in the first domain are magnetic interaction and right hand rule where four links are attached to each of them. According to first domain of figure 1, Kevin showed how the concepts of magnetic field, electric current, moving charges, and pair long wires contribute to understanding magnetic interaction as follows:

- Magnetic interaction can be described by magnetic field; moving charge undergoes magnetic interaction; electric current can cause magnetic interaction, and pair long wires have a magnetic interaction.

Likewise, as the outgoing links from the concept of right hand rule shows:

- Right hand rule expresses the relationship between magnetic field, moving charges, wire carrying current, and force.

The second relevant domain encompasses two central concepts (coil and magnetic field), where three links are linked to each of them. Following the links connected to coil, the concepts of magnetic field, area, and electric current are attached to it:

- $\quad$ Electric current in a coil causes a magnetic field; and coil has an area.

Similarly, as the incoming links to magnetic field show, Kevin depicted how the concepts of coil, magnetic flux, and magnetic flux density are linked to magnetic field:

- Magnetic flux density is another way of thinking about magnetic field; magnetic flux describes the concentration of magnetic field; and as mentioned before, coil creates a magnetic field. 
As an indication of paralleled OrgK in 'pure' physics, two concept maps from the high school physics textbook (Hatakka et al, 2008) are considered for comparison. This enables us to understand the differences between OrgK from the pure discipline and OrgK that has been moderated by an experienced physics teacher already.
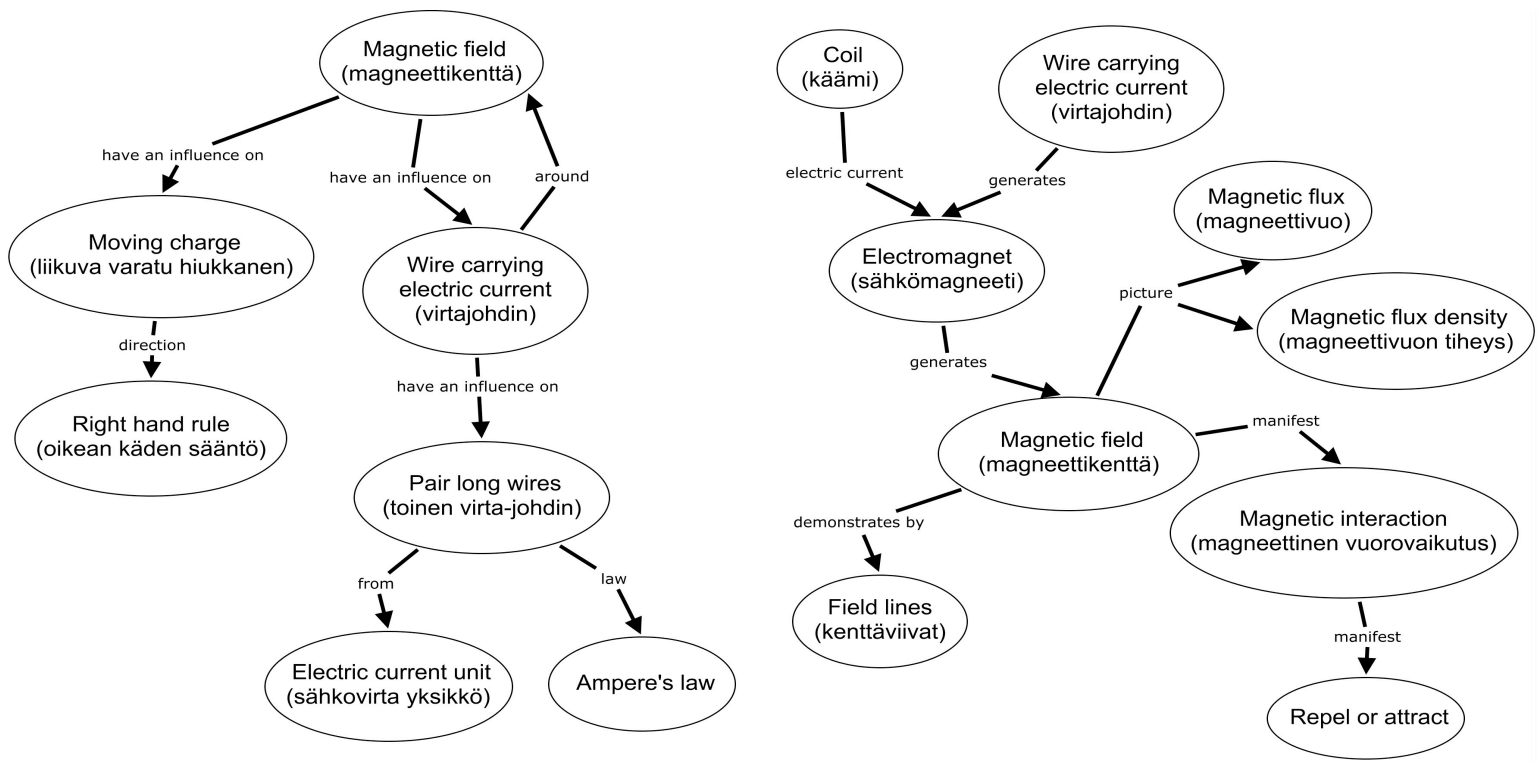

Figure 2. Redraw concept map from textbook (p. 24 and p. 43 from Hatakka et al, 2008)

The codified interrelations and connections of the same thirteen concepts Kevin had at his disposal can be read from figure 2. In order to investigate the differences between OrgK of Kevin (figure 1) and textbooks (figure 2), the concepts that are connected to Kevin's core concepts are assessed and presented in Table 4.

Table 4. Comparing the connected concepts to main cores within the concept maps of teacher and textbook (shared concepts appear in italics)

\begin{tabular}{lll}
\hline Core Concepts & In concept maps of Kevin & In concept maps of Textbook \\
\hline Incoming links to & Wire carrying current & Wire carrying current \\
& Magnetic flux & Electromagnetic \\
& Magnetic flux density & \\
& Magnetic interaction & \\
& Coil & \\
& Right hand rule & \\
\hline Outgoing links from & Field lines & Magnetic flux \\
Magnetic field & Density of field lines & Magnetic flux density \\
& & Field lines \\
Magnetic Interaction & Electric current & Magnetic interaction \\
\hline Incoming links to & Moving charge & Moving particles/charge \\
\hline
\end{tabular}




\section{Pair long wires}

Outgoing links from Magnetic field

Magnetic Interaction

There are some differences between the ways that the teacher and the textbook arrange the magnetostatics concepts. For example as Table 4 shows, in the textbook, right hand rule is connected to magnetic field via moving charge. So it is not imagined as either incoming or outgoing links from magnetic field. On the other hand, moving charge is directly connected to magnetic field so it is an outgoing link from magnetic field. In a different perspective, for Kevin's case, right hand rule as an incoming link to magnetic field is connected to each, moving charge and magnetic field, directly (Table 4). In addition, in textbook, coil connects to magnetic field through electromagnetic so it is not an incoming or outgoing link to magnetic field. But Kevin stated that coil creates a magnetic field so he directly connected coil as an incoming link to magnetic field.

In contrast to the textbook, Kevin connected moving charge, electric current, and pair long wires to magnetic interaction (Table 4). In textbooks' map, the concepts of electric current and pair long wires indirectly (Figure 2) and moving charges directly (Table 4) are linked to magnetic field instead of magnetic interaction. This difference perhaps indicates a difficulty of distinction between magnetic field and magnetic interaction. Although there are differences between incoming and outgoing links, more similarities between OrgK of teachers and textbook for explaining magnetic field have been recognized in comparison to explanation of magnetic interaction (Table 2).

Responses to questions regarding Representation Forms

The responses of both teachers to the questions about ReFs for teaching Ampère's law and magnetic flux density (moving charge or electric current) gave information which is presented in Table 5.

Table 5. Responses of teachers to questions regarding Representation Forms (ReFs) for teaching Ampère's law and magnetic flux density.

\begin{tabular}{|c|c|c|c|}
\hline Representation forms & & Robert & Kevin \\
\hline \multirow{4}{*}{$\begin{array}{l}\text { Applications } \\
\text { examples }\end{array}$} & \multirow[t]{4}{*}{ or } & Magnetic flux density: & Magnetic flux density: \\
\hline & & $\begin{array}{l}\text { A wire "swing" in a vertical } \\
\text { magnetic field }\end{array}$ & - \\
\hline & & Ampère's law: & Ampère's law: \\
\hline & & $\begin{array}{l}\text { Definition of unit Ampere, } \\
\text { currents in a lightning }\end{array}$ & $\begin{array}{l}\text { Wire. Loop, Coil, Velocity } \\
\text { Selector, Hall Effect, Cyclotron, } \\
\text { Mass Spec, Magnetic Bottle }\end{array}$ \\
\hline \multirow{4}{*}{$\begin{array}{l}\text { Explanations } \\
\text { justifications }\end{array}$} & \multirow[t]{4}{*}{ or } & Magnetic flux density: & Magnetic flux density: \\
\hline & & - & Faradays law and Lenz's law \\
\hline & & Ampère's law: & Ampère's law: \\
\hline & & $\begin{array}{l}\text { A demonstration with light } \\
\text { vertical wires }\end{array}$ & $\begin{array}{l}\text { We get a deflection in a magnet } \\
\text { qualitatively }\end{array}$ \\
\hline \multirow[t]{4}{*}{ Analogies } & & Magnetic flux density: & Magnetic flux density: \\
\hline & & - & Flowing water through a ring \\
\hline & & Ampère's law: & Ampère's law: \\
\hline & & Interaction between two bar & The magnetic field of \\
\hline
\end{tabular}


magnets and comparing the solenoid and bar magnet magnetic fields of the two

\begin{tabular}{lll}
\hline Experiments & Magnetic flux density: & Magnetic flux density: \\
& $\begin{array}{l}\text { A wire "swing" in a vertical - } \\
\text { magnetic field }\end{array}$ & \\
& Ampère's law: \\
& $\begin{array}{l}\text { Magnetic field between two Qualitative ones, they do not } \\
\text { vertical wires } \\
\text { have the math yet... }\end{array}$ \\
\hline Students' difficulties & $\begin{array}{l}\text { Using the right hand rule } \\
\text { correctly }\end{array}$ & $\begin{array}{l}\text { The concept of induced flux is } \\
\text { tricky }\end{array}$ \\
\hline
\end{tabular}

Teachers' responses to the questions about ReFs for teaching magnetic flux density are given here. Robert posited that a wire "swing" in a vertical magnetic field is a good example or application of this Ampère's law. Kevin stated that Faraday's law and Lenz's law are good explanations or justifications for teaching this topic. He also stated that flowing water through a ring can be used as an analogy for teaching this topic. As examples of students' difficulty and misconceptions Kevin argued that the concept of induced flux is tricky and Robert stated that using the right hand rule correctly is challenging for students.

Teachers' responses to the questions about ReFs for teaching Ampère's law are given here. Kevin posited that (magnetic fields of) wire, loop, coil, velocity selector, Hall Effect, cyclotron, Mass Spectrum, Magnetic Bottle are good examples and applications of Ampère's law. Unlike Kevin, Robert expressed that a definition of the unit Ampère and currents in a lightning wire are good applications and examples for teaching Ampère's law. Kevin stated that "getting a qualitative deflection in a magnet" is a proper justification for teaching Ampère's law, while Robert reported that "a demonstration with light vertical wires" is a better case about this. Kevin stated that "qualitative experiments which do not have the math yet" are the most appropriate experiment, while Robert stated that the experiment with "two vertical wires" is a suitable one.

As a final remark, Kevin claimed during teaching these topics he first demonstrates, and then he continues with theoretical analysis of the force on a wire in magnetic field. On the other hand, Robert stated that the following items are essential in his teaching 1. demonstration, 2. law, 3. Examples and analogies, 4. calculations. So both teachers stressed the value of demonstration and its priority to theoretical analysis and explanations.

\section{Representation Forms from observed lessons}

Two lessons regarding magnetic flux density and Ampère's law were videotaped in two days, each lesson took 75 minutes. The lessons were given to students from the last grade of high school whose age was between 17 and 18 years.

Robert started by asking a question to activate students' knowledge about the direction of magnetic field lines regarding the north and south poles of a bar magnet. Then he sketched the magnetic field using field lines on the board. He led to explaining the difference of the electromagnetic fields of a long straight wire and a coil. He did so by drawing their magnetic field lines. With regard to this, he emphasized strongly the direction of current that passes through the wire or coil and illustrated the right hand rule to determine the direction of the field lines. Next, he brought up the magnetic field of the earth as an example.

"Earth is a big electric magnet; ionized molten matter flows inside the earths' centre, this causes a flow of electricity, this 'dynamo effect' causes the magnetic flow"

He drew a figure that represented earth's magnetic field and gave an explanation of its generation:

"A current loop goes around the equator, this current loop runs approximately parallel to the plane of the equator, current flows in the direction of the rotation of the earth, it (electric flow of the earth) is like that of a 
current wire that creates a magnetic field, there is current circulating inside the earth, therefore, there is a magnetic field, that (points to sketch on board) is how the magnetic field of the earth looks like."

In what follows, some selected instances are given from which we can read Robert's use of ReFs, the way he taught the topics of magnetic flux density for moving charges and current carrying wires as well as Ampère's law. The related excerpts from the lesson observation are presented here.

\section{Representation Forms regarding Magnetic Flux Density for Moving Charges}

In order to show the effects of magnetic force on moving electrons Robert used an oscilloscope for his demonstration. He emphasized that it was not used for measuring but for illustrating magnetic force on moving electrons. He put a bar magnet close to the screen of the oscilloscope so students saw that the stream of electrons hitting the screen was disturbed by the magnet (figure 3):

"As you see, the magnet disturbed the movement of the electron. We can make a simple conclusion! There is a force inherent in the bar's magnetic field and it exerts on electrons"
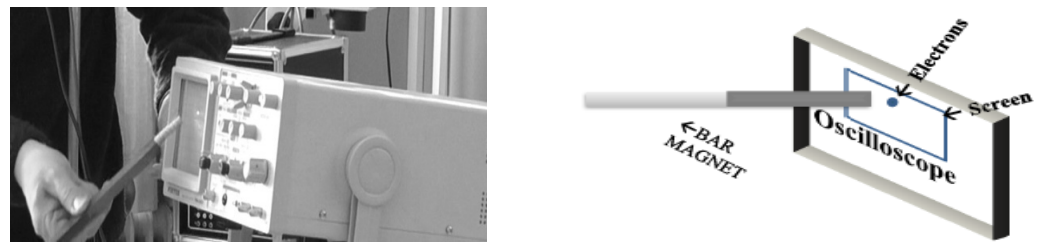

Figure 3. Using the oscilloscope and a bar magnet to show magnetic force on moving electrons

Also he demonstrated and stated the fact that displacement will be zero when a magnet is close to electrons, i.e. the exacted force on the electron stream will equal zero. In analogy, he mentioned cathode-ray TV-sets as everyday applications comparable to the oscilloscope.

After having introduced formulaic expressions relating magnetic force (F), magnetic flux density (B) and speed of charged particles (v), he highlights the link between mathematics and the outcome from experiments:

"It is inherent in the vector in mathematics that $F$ is perpendicular to $B$ and $v$. So mathematics goes along with what we understand experimentally."

\section{Representation Forms regarding Magnetic Flux Density for a Conductive Wire}

In order to illustrate the magnetic force exacted on a conductive wire, Robert used a second experiment with a horseshoe magnet and two wires connected to a power supply and an aluminium rod. The aluminium rod was suspended freely between the magnet's two poles (figure 4).
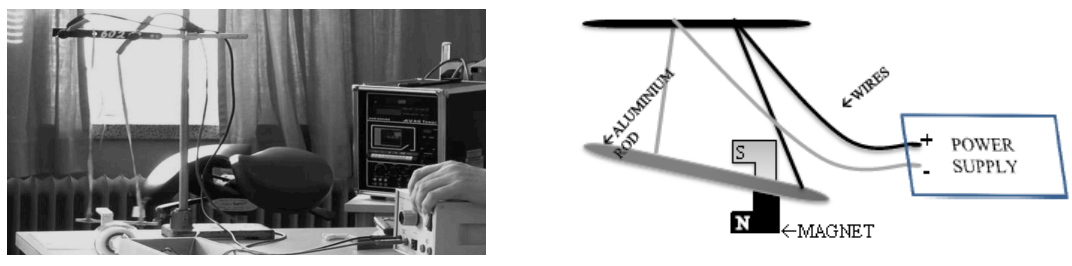

Figure 4. Force inserting on a straight long wire on a straight long wire

Robert asked his students to observe changes when (dis-)connecting the power supply. He visually deduced the direction of the magnetic force causing the rod's motion, and then mathematically described the magnitude and direction of the force. Then, he described the direction of a magnetic field of a wire visually, and its corresponding equation mathematically. The conducted experiment is consistent with what Robert posited in questionnaire: "A wire swing in a vertical magnetic field" can be used as the explanation or justification or an appropriate experiment regarding teaching magnetic flux density.

Representation Forms regarding Ampère's law

Robert chose a third experiment to demonstrate Ampère's law using two wires carrying current (figure 5). 

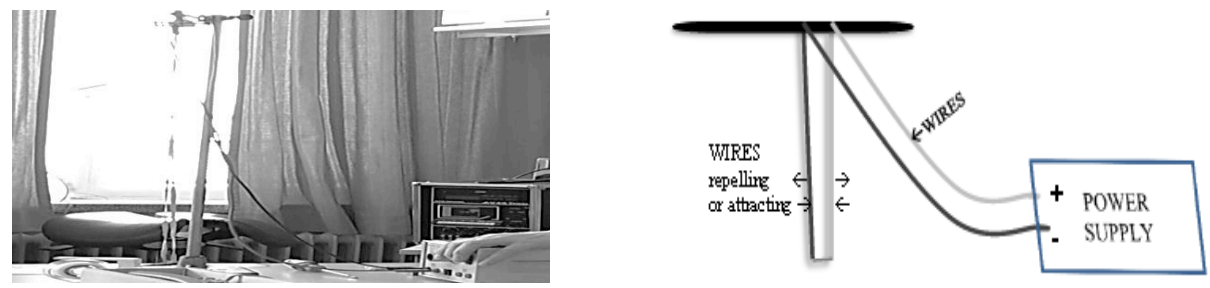

Figure 5. Experiment of Ampère's law using magnetic interaction between two wires carrying current.

He posed questions about the direction of current in the wires:

"Both wires are connected to the power supply and to each other. How does the current flow through each wire? When currents flow, do they go in the same or opposite directions? Who can say in which directions currents move?"

Next he conducted the experiment and made students observe before he mathematically explained Ampère's law. This is an illustrative example of Robert's employing the experiment by predictions, observation, and experiment (PEO) (Loughran et al, 2004). A demonstration with light vertical wires was both an appropriate justification or explanation and suitable experiment for teaching Ampère's law from Robert's point of view.

In summary, analysing the videotaped lessons and the responses to the questionnaire suggest an improved way of approaching ReFs that transcends the level of modality. We consider ReFs to be describable at least two-dimensionally in terms of "form/character of discourse" (state, explain, describe etc.) and "medium of instruction" (model, experiment, facts etc.). This view might give prospective teachers wider perspective on the potential variety that there is when dealing with, e.g., mathematical models. As the teachers' part need not be restricted to 'Stating' them but might extend to 'Explaining' them, this approach might be a valuable way of operationalizing ReFs and keeping a structured and focused view. These categories are not exclusive and are open to extension and refinement (see figure 6). These categories are inspired by representation forms that discussed in Table 1 and by representation forms of university physics teachers suggested by Majidi (2012). She identified that experiments, statement of facts, explanatory and descriptive mathematical models, visual models, reasoning, and analogies were the most employed representation forms which teachers used as a part of their SMK to formulate PCK.

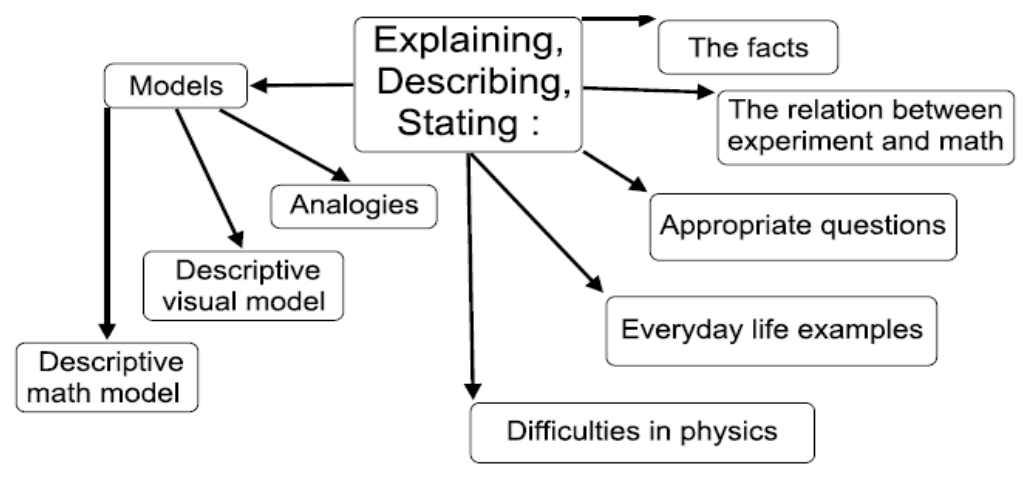

Figure 6. Recognized categories of representation forms (ReFs) of teachers from questionnaires and lessons observations.

The results of this study which emerged from analysis of questionnaires and observations of lessons correlate with information provided in Table 1: these categories are in the same line with arguments of Shulman's (1986), Geddis and Wood (1997), Loughran et al (2004), and Hashweh (2005) who stated ReFs includes analogies, illustrations, examples, explanations, simulations, and metaphors. 


\section{Discussion and conclusion}

Our survey started from considering teachers' OrgK and extended toward their preferred ReFs.

The first question concerns teachers' OrgK of "magnetic flux density" and "Ampère's law". We assume that without being able to organize the content knowledge for themselves, it is hard for teachers to convey knowledge to students in a structured fashion. As Gess-Newsome (1999a) stated, having organized knowledge allows teachers to "envision longer periods of instruction planning." This study aimed at triangulating data on OrgK and ReFs and, therefore, employed different modes of survey: questionnaire, concept map, and observation.

Results from the teachers' responses to the questionnaire indicated harmony between the OrgK of Kevin and Robert, which suggests that there is something like a consensus OrgK for secondary +physics education. Disagreement over ordering in singular instances (magnetic flux density, magnetic density, moving charges, Ampère's law) might be attributed to teachers' individual philosophies of teaching (phenomenological vs. formulaic).

The second question was concerned with representation forms that teachers employ in order to translate their SMK, which is considered to be a main feature of their PCK (Shulman, 1986; Geddis \& Wood, 1997). We could confirm several of priories suggested ReFs (Majidi, 2012) through analysis of taped lessons and suggest extending describing ReFs by considering not only their medial representation but also the form of discourse they appear in. Different ReFs that physics teachers utilize for translating SMK were extracted, and it must be borne in mind that this list cannot be considered exclusive as it stems from limited observation data. The ReFs influence one another in a contextually bound way. This case study, herein, showed teachers integrate these components and enact them within the context of magnetostatics. The integration of these components can presumably be achieved easier if teachers possess a rich OrgK. The ReFs and OrgK discussed in this study can be in particular useful for other physics teachers or for science teachers in general. ReFs which perform as a source of PCK and OrgK which functions as a source of SMK, influence each other. The possible integration between teachers' OrgK and ReFs, which we would like to suggest, are given in figure 7:

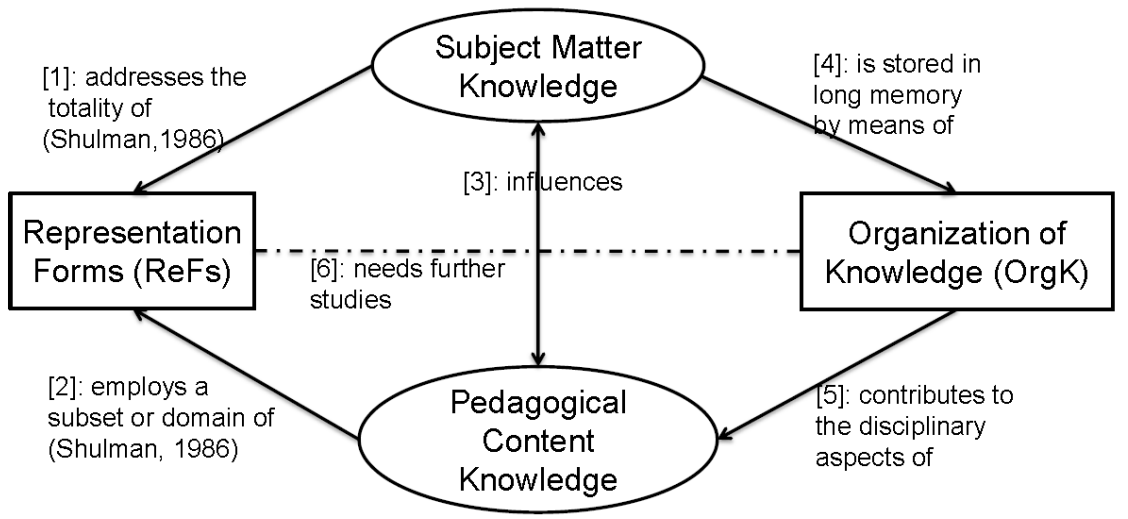

Figure 7. Schematic view of the place of representation forms ReFs and organization of knowledge OrgK in teachers' SMK and PCK.

Some researchers claim (Hashweh, 2005; Loughran et al. 2006; Rollnick et al. 2012) that SMK addresses the totality of ReFs ([1] in figure 7). As some ReFs are more suited for teaching purposes than others, e.g., from academic discourse, at least a subset of ReFs falls into teachers' PCK. These ReFs concern teachers' strategies of translating their SMK for their students ([2] in figure 7, Shulman, 1986; Geddis \& Wood, 1997).

The influence of SMK and PCK has been discussed in many studies (Shulman, 1986; van Driel et al, 1998; Hashweh, 2005; Abell, 2007; Rollnick et al, 2008) and it has been suggested that SMK is either a distinct category or a component of PCK ([3] in figure 7). As a result, the connections between ReFs, PCK, and SMK construct a meaningful triangle. If we take our survey of OrgK to be indicative of SMK we would back the idea, that SMK and PCK are related as there were matching structures observed to be present in textbook representations and teachers' self-assessment. This is sensible, considering that SMK is likely to be stored in teachers' long term memory (Bransford et al. 1999) by means of OrgK ([4] in figure 7). This enables teachers to easily retrieve the content knowledge on a need-to-basis, i.e. in instructionally relevant contexts. They can answer to a variety of students' 
questions more easily, even if most often the correct answers of students refer to other topics and sometime other grades than the referent age their OrgK has been constructed for. Having an organized knowledge enables the teacher to link specific content to other topics in more flexible ways. In this respect teachers' SMK is approximating PCK as it becomes education-bound, if only in extracts ([5] in figure 7). If we once again focus in on the debated connection between PCK and SMK, we would, therefore, argue for a second meaningful triangle, in which SMK and PCK are connected through OrgK.

The method developed herein integrates teachers' idea about magnetostatics concepts, their ways to frame and organize those concepts (OrgK), and finally their representation forms (ReFs) to translate their SMK as a part of their PCK. The categories of OrgK and ReFs can enhance teaching of science teachers especially physics teachers. These notions have the potential to give more depth and breadth to science teachers' SMK and PCK (Shulman, 1986; Geddis \& Wood, 1997; Loughran et al, 2004; Hashweh, 2005; Rollnick et al, 2008). However, more researches is required to be done in this regard ([6] in figure 7).

The limitations of this study come from the necessity to restrict to two cases. Still we see potential in perpetuating research on how OrgK and ReFs influence each other. We have gathered some ideas from comparing two differently oriented (philosophy of teaching) and organized (OrgK) teachers who have shown idiosyncratic choices of preferred ReFs. As a perspective, we should observe how integration of OrgK and ReFs is related to students' learning which goes along with Geddis and Wood (1997) research.

Ultimately, our conceptualization of ReFs underlines the importance providing categories for representing SMK in class (Geddis \& Wood, 1997), which is a crucial part of teachers' PCK. Teacher educators must be aware of the most suitable ReFs that are applied for particular topics, by doing this they can enhance guiding pre-service and in-service teachers according to their individual needs.

It has often been stated that PCK is at the heart of teachers' professions; considering that SMK has a direct bearing on domain-specific evolution of PCK, it must be stated clearly that SMK must not be neglected in any way in teacher education. Pedagogical skills and ReFs are merely a bow for teachers - the arrows in their quivers come from SMK.

\section{Acknowledgements}

This study is supported by Thesis Completion Grant (2013), Faculty of Science, University of Helsinki. We would like to express our special thanks towards the organizers of Graduate School Meetings in Hamburg (2011) and Essen (2012). Thanks to Tommi Kokkonen for his help to translate the lessons into English.

The summary of this study is accepted to be orally presented in European Science Education Research Association (ESERA), 2013 in Nicosia, Cyprus

\section{References}

Abell, S. K. (2007). Research on Science Teacher Knowledge. In Abell, S. K., Lederman, N. G. (Ed.), Handbook of Research on Science Education, Ed., Chapter 36, (pp. 1103-1149). New York: Routledge.

Bransford, J. D., Brown, L. A., and Cocking, R. R. (1999). How people learn: brain, mind, experience, and school. Washington, D.C.: National Academy Press.

Carter, K. (1990). Teachers' knowledge and learning to teach. In W. R. Houston \& M. H. J. Sikula (Eds.), Handbook of research on teacher education (pp. 291-310). New York: Micmillan.

Erickson, G. (1994). Pupils' understanding magnetism in a practical assessment context: The relationship between content, process and progression. In P. Fensham, R. Gunstone, \& R. White (Eds.), The content of science. London: Falmer.

Geddis, A. N. and Wood, E. (1997). Transforming Subject Matter and Managing Dilemmas: A Case Study in Teacher Education. Teaching and Teacher Education, 13, 611-626.

Guisasola. J., Almudì. J. M., and Zubimendi, J. L. (2004). Difficulties in learning the introductory magnetic field theory in the first years of university. Science Education, 88, 443-464.

Hashweh, M. Z. (2005). Teacher Pedagogical Constructions: A reconfiguration of pedagogical content knowledge. Teachers and Teaching: Theory and Practice, 11, 273-292

Hatakka, J., Saari, H, Sirviö, J.,Viiri, J, and Yrjänäinen, S. (2008). Physica 7, Sähkömagnetismi. Porvoo: WSOY Oppimateriaalit.

Hay, D. B., Harvey, W., and Kinchin, I. M. (2008). Quantitative and qualitative measures of student learning at university level, Higher Education, 56, 221-239.

Kagan, D. M. (1990). Ways of evaluating teacher cognition: Inferences concerning the Goldilocks principle. Review of Educational Research, 60, 419-469.

Kinchin, I. M., Hay, D. B., and Adams, A. (2000). How a qualitative approach to concept map analysis can be used to aid learning by illustrating patterns of conceptual development. Educational Research, 42 (1), 43-57.

Koponen, I. T., and Pehkonen, M. (2010). Coherent Knowledge Structures of Physics Represented as Concept Networks in Teacher Education. Science \& Education, 19, 259-282. 
Loughran, J. Mulhall, P. and Berry, A. (2004). In search of pedagogical content knowledge in science: Developing ways of articulating and documenting professional practice. Journal of Research in Science Teaching. 41, 370-391.

Majidi, S. and Mäntylä, T. (2011). The knowledge organization in physics textbooks: A case study of magnetostatics. Journal of Baltic Science Education, 10(4), 285-299.

Majidi, S. (2012). Structural patterns and representation forms of university physics teachers: Biot-Savart Law and Ampère's law. Journal of Baltic Science Education, 11 (4), 318-332.

Manogue, C. A., Browne, K., Dray, T., and Edwards, B. (2006). Why is Ampère's law so hard? A look at middle-division physics. American Journal of Physics, 74, 344-350.

Mäntylä, T. (2011). Didactical Reconstruction of Processes in Knowledge Construction: Pre-service Physics Teachers Learning the Law of Electromagnetic Induction. Research in Science Education, 42, 791-812.

Novak, J. D., and Canas, A. J. (2006). The Origins of the Concept Mapping Tool and the Continuing Evolution of the Tool. Information Visualization, 5, 175-184.

Rollnick, M., Bennett, J., Rhemtulaa, M., Dharseyc, N., and Ndlovua, T. (2008). The Place of Subject Matter Knowledge in Pedagogical Content Knowledge: A case study of South African teachers teaching the amount of substance and chemical equilibrium. International Journal of Science Education, 30, 1365-1387.

Rollnick, M., Mundalamo, F., and Booth, S. (2012). Concept Maps as Expressions of Teachers' Meaning-Making while Beginning to Teach Semiconductors. Research in Science Education, 10.1007/s11165-012-9314-1

Shulman, L. (1986). Those who understand: Knowledge growth in teaching. Educational Researcher, 15(2), 4-14.

Stoddart, T., Abrams, R., Gasper, E., and Canady, D. (2000). Concept maps as assessment in science inquiry learning-a report of methodology. International Journal of Science Education, 22(12), 1221-1246.

Trends in International Mathematics and Science Study (TIMSS) Advance 2008. http:/ / timssandpirls.bc.edu/timss_advanced / downloads/T08_TeacherQ-Physics.pdf

van Driel, J., Verloop, N., and de Vos, W. (1998). Developing science teachers' pedagogical content knowledge, Journal of Research in Science Teaching, 35(6), 673-695. 